\title{
Research on Evaluation System Reform of Toxicology Experimental Teaching
}

\author{
Huayi Suo ${ }^{1,2}$ \\ ( ${ }^{1}$ College of Food Science, Southwest University, Chongqing 400715, China; \\ 2. National Food Science and Engineering Experimental Teaching Center, Southwest University, \\ Chongqing 400715, China)
}

Keywords: Toxicology; Experiment; Evaluation system; Teaching reform

\begin{abstract}
Objective: As a subject with strong practicability, the toxicology of food emphasizes the mastery and actual application of experimental operation ability in teaching. However, the learning initiative of students is not high and learning effect of students is poor during the real experimental teaching process due to the learning method and experimental evaluation mechanism. Methods: The reform is carried out against teaching method, appraisal index and mode of toxicology experiment in this research. Through the implementation for a series of measures during the practice process, such as the seamless connection between theoretical courses and experimental courses, control of experimental operation process, timely summary of experimental problems and adjustment of experimental evaluation system, etc. Results \& Conclusions: It is found that this series of teaching reform measures can improve learning initiative and learning effect of students effectively.

Nowadays, science and technology are growing in leaps and bounds. The era of knowledge-driven economy brings a more fierce global competition. However, all the competitions are the talents' competition finally. The national comprehensive competitive ability can become stronger only if the high-quality scientific and technological talents are obtained. As a carrier to cultivate the talents, the institution of higher education should pay a sufficient attention to the construction of campus culture to provide a wide space and scientific guidance for the creation of talents. How to cultivate the innovative talents owning practice foundation and innovation ability is a great challenge which the higher education should face.

Food toxicology is an interdiscipline with strong practicalness. It is mainly applied in the theory and the technology of basic subjects like physiology, pharmacology, biology, biochemistry and pathology etc. Meanwhile, it researches the absorption, distribution, metabolism, excretion, toxic effect and its mechanism as well as intoxication treatment through animal experiment, clinical observation and epidemiological investigation so as to protect the human and other organisms from the deleterious effect of chemical substances and protect the health of people. Consequently, the teaching requirement of food toxicology must conform to the current demand to foster the ability of students with strong practical foundation and independent innovation and provide the high-level interdisciplinary talents for the society.
\end{abstract}

\section{Problem Which the Experimental Teaching of Toxicology Faces}

In China, the higher education pays more attention to theory and knowledge instruction than practice and ability cultivation. The talents cultivated are lack of innovation consciousness and high innovation ability, which has a large gap with the social requirement. This is reflected in the insufficient attention to experimental teaching and the weak teacher staffing. The experimental teaching is an auxiliary for theoretical teaching, no leading role. The problems existing in the cultivated graduates is more obvious. In the process of undergraduate thesis experiment in the senior, the problems incapable of reagent preparation, experiment design and pertinent literature search etc. often arises. The failure to grasp the basic experiment skill has resulted in the unseeing of graduates and the decline of employment rate when they graduate. This shows that there are many problems in the current experimental teaching system and pattern of food toxicology.

The Shortage of Class Hour on Experiment Course Results in the Overgeneralization on Experiment Setting. The associativity is insufficient between experiments. Students cannot grasp 
and apply the method to solve problems comprehensively [1, 2]. At present, the college experiment always verifies the knowledge point of one or certain teaching or the correctness of certain known function through one experiment. It always is isolated among each experiment. After completing an experiment, the students have understood and grasped a knowledge point to certain degree. However, they still have no idea how to connect each knowledge point and use them comprehensively so as to complete the integrated experiment and solve the problem existing in practice [3].

Old-fashioned Experimental Content and Delayed Update. Food toxicology is a traditional major. The scientific and technological development is rapid. But the experimental teaching material for this major is lagging relatively. The connection between theory and practice is not close. Moreover, it also is lack of targeted experiment guidance. The actual problems in current production and living cannot be reflected well. Such old-fashioned experimental content has restricted the experiment enthusiasm and creativity of students seriously.

Old-fashioned Experimental Teaching Method. From the point of teaching method, the students always are in a passive position in the selection of experimental content, the setting of instrument and equipment, the preparation of experiment reagent etc. They have no choice but subject to the arrangement of teacher responsible for experiment. In the whole process of experiment, the students only can complete it in accordance with the experimental procedures successively to get the expected results. The whole process is lack of thinking and high participation enthusiasm due to the known experimental results [4].

The Assessment Method of Experiment Restricts the Enthusiasm of Students. At present, the assessment for experiment mainly adopts the method combining experiment report and attendance checking. It has the disadvantages as follows: (1) do not operate conscientiously in the process of experiment. Rely on other group members to complete the experiment and respond to the experiment under the state of "body in experiment but thought gone". (2) In the process of experiment, do not operate conscientiously or do experiment personally as onlooker. Plagiarize the experimental report, result and data of others. The experimental report always is similar. It is difficult to figure out the students conscientiously doing experiment and grasping the experimental skill through their score. Generally, the students with a neat handwriting always are given a high score. This is not fair and impartial.

Under the current assessment system of experimental teaching, it's difficult to arouse the enthusiasm and creativity of students for experiment. This cannot promote students to understand the experiment comprehensively and devote themselves to the experimental teaching. At present, it needs urgently to seek a new teaching model and assessment method so as to improve the experiment skill and innovation ability of students comprehensively.

\section{Research and Practice}

Introduce the "practice-oriented PBL teaching method" into the experimental teaching of higher-education institution [5,6] to change the traditional teacher-oriented teaching pattern and make students to become the main body of teaching activity. Develop the learning enthusiasm of students and orient by the production practice and the problems existing in scientific research to improve the learning initiative of students fundamentally and their experimental skill comprehensively.

First, how to combine the experiment project and the actual production in the design of experiment course to design the experiment situation is the key point to improve the learning initiative of students. We should make students to realize the high practice value of corresponding experiment, that the problem existing in production also can be solved through learning and how to guide them to think as a production technician or scientific researcher. Meanwhile, we also need to exploit and broaden the view of students in the early state to make them to get the ability of analyze problems and know they can play the social role and stand in the society through learning.

Secondly, the teacher should change the course role in the process of educational reform, namely the transformation from inculcation to guidance. This change requires the teacher should own more 
production practice and scientific research experience. It is necessary to complete the transformation through the efforts that the teacher participates in the actual production and scientific research continuously. Meanwhile, it also a high enthusiasm of teacher for experiment teaching and students.

At last, the purpose to apply the new assessment method of experiment course is to make students to grasp and improve the experiment skill comprehensively. Therefore, at the early stage to commence the course, we should make students to know the assessment method and standard. Meanwhile, it is also required to add the experiment hour additionally so as to complete the final assessment.

We pay a particular attention to the ability cultivation of students to perform experiment, mainly including three ability levels: (1)basic experiment skill: the key point is to make students to grasp the general operating skill of animal experiment (including sex determination, fetching and fixation, collection, intragastric gavage and killing of experiment materials etc. ), acute oral LD50 determination and micronucleus test etc. The students should be capable of right apparatus using and data collection. They also should own the ability to get experimental data and correct conclusion. (2)Improving-oriented experiment ability: the key point is to make students incapable of using multiple experiment methods and measures to realize the purpose of one experiment. Get the experiment information through multiple ways and own the ability to operate independently, make analysis and reasoning and solve the actual problem as well as the ability to obtain experiment data, conclusion and solve the problem through experimental design and plan the experimental scheme by themselves. (3)Innovative experimental ability: the key point is to make students to do an exploratory experiment under the guidance of teacher so as to own the ability to seek truth from facts, explore and innovate.

\section{Innovation Point}

Innovation of Experiment Content. Under the principle to comply with the integrity, comprehensiveness and representativeness of experiment content as well as the multiformity of experimental method, select the experiment content as follows: (1)counting of hemocyte; (2) common exposure method to toxicant in acute toxicity test and determination of medium lethal concentration; (3)collection and dissection of experimental animal and biological materials; (4) screening of specimen preparation for medullary cell micronucleus of mouse. The students can verify certain toxicological theory through completing the above experiment. Moreover, they also can understand and grasp some basic experimental technique. It is advantageous to cultivate the students' ability to observe, analyze, solve problem and operate through observing the expression and reaction of experimental animal to really get the true meaning of combination between theoretical knowledge and practice.

Innovation of Experimental Method. In the teaching of toxicological experiment, we adopt the combined teaching method that the student teaches and the teacher supplements. Before each experiment, select a group of students randomly ( 2 students per group) or the student participating in preliminary experiment to explain the experimental principle, method and operating procedures. Then other students raise questions. Make a comprehensive assessment based on the situation that each group answers questions and teaches. At last, the teacher is responsible for supplementing and concluding. The students like this method very much and the teaching effect is obvious.

Open the experimental teaching and set the chosen course. Open the training room for basic skill and the operating room for common instrument in batches and regularly to ask the students to complete each basic skill training independently. Open the laboratory for students to make innovation and research all day to encourage students to develop the scientific research project by themselves and participate in the scientific research of teacher. Set the chosen experiment to offer the class or the individual with different majors and course hours to choose and make in accordance with their own interest and research.

Innovation of Experiment Assessment. Establish a multivariate assessment method for experiment to assess its course and result comprehensively. The assessment at ordinary times 
accounts for $50 \%$, including $10 \%$ in experimental habit, $20 \%$ in operation, $10 \%$ in result and $10 \%$ in report. The experimental design and the practical operating examination at the end of term also accounts for $50 \%$.

\section{Actual Application}

From January, 2014 to June, 2015, PBL teaching method oriented by practice was adopted to make an exploratory research for the teaching reform of one to two experiment courses of Food Toxicology in food quality and safety major. The research was carried out in three classes (about 90 students).

First, the teaching content of experiment was improved. At present, the setting emphasis of toxicological experiment course related to food science in each college and university is different. Some of them pay attention to detection and inspection (such as the detection of some toxin etc.) while some lay emphasis on animal experiment. According to the discipline characteristic of food quality and safety major, our teaching and research office holds the opinion that the experiment of food toxicology opened by this major should take the animal experiment as main content. Under the principle to comply with the integrity, comprehensiveness and representativeness of experiment content as well as the multiformity of experimental method, select the experiment content as follows: (1)counting of hemocyte; (2)common exposure method to toxicant in acute toxicity test and determination of medium lethal concentration; (3)collection and dissection of experimental animal and biological materials; (4)screening of specimen preparation for medullary cell micronucleus of mouse. The students can verify certain toxicological theory through completing the above experiment. Moreover, they also can understand and grasp some basic experimental technique. It is advantageous to cultivate the students' ability to observe, analyze, solve problem and operate through observing the expression and reaction of experimental animal to really get the true meaning of combination between theoretical knowledge and practice.

Secondly, the teaching method of experiment is improved. The teaching of experiment for food toxicology mostly adopts the traditional teaching method in which the teacher explains the experimental theory and method first, then demonstrates the experiment operation. At last, students complete the experiment in accordance with the procedures and method set by their teacher. The teacher plays a leading role in such method while students are in a passive learning, which is not beneficial to the enthusiasm and initiative cultivation of students and disadvantageous to improve the ability of student to analyze and solve problems, either. For this purpose, we adopts the teaching method combined by student teaching and teacher supplementing for the experiment of food toxicology. Before each experiment, select a group of students randomly ( 2 students per group) or the student participating in preliminary experiment to explain the experimental principle, method and operating procedures. Then other students raise questions. Make a comprehensive assessment based on the situation that each group answers questions and teaches. At last, the teacher is responsible for supplementing and concluding. The students like this method very much and the teaching effect is obvious. The initiative of students for experiment course has been improved greatly. In the process of operation, they become more careful and serious. The phenomenon that the student doesn't prepare the course or prepare insufficiently before class has been improved a lot including the learning atmosphere. The purpose and the requirement to do experiment have been realized really through completing the experiment.

At last, improve the method to assess the teaching of experiment. In the past, the experimental teaching only was taken as the supplementary part for the theoretical teaching of toxicology. It was not assessed or the proportion in the final total score is lower. This made the students to pay more attention to theory and less on practice and the effect of experiment teaching was not ideal. Consequently, we gradually increase the assessment proportion of practice course to $40 \% \sim 50 \%$. In addition, the past assessment method for experiment of food toxicology only used the experiment report. With the adjustment and improvement of teaching content and method, the assessment result of experiment becomes the one combined by the experiment score at ordinary times and examining 
and designing result from the one at ordinary times. The last experiment course is an assessment one. Tell students the topic of designing experiment one week in advance to let them search literature, design experiment scheme and complete the experiment in class. The score accounts for $50 \%$ of total score of course. To assess through both combination can better reflect the actual experimental level of students while obtaining the recognition from students.

\section{Practice Experience}

Seamless Connection Between Theoretical Course and Experimental Course. It is required to do the test for animal experiment because of particularity of toxicological experiment. The experiment itself has a certain dangerousness. In addition, some students fear of laboratory mouse. Before the experimental course commences, make an introduction to the experiment content and provide each student the self-complied experimental teaching materials. Meanwhile, the students are not allowed to write the experimental report. The experimental video is taken to display in the class and explain the operating points of experiment. On the one hand, this has realized the seamless connection between classroom teaching and experiment one. It also has combined the scientific research to lead the students in understanding the experimental principle and operation sufficiently. On the other hand, this has prepared a psychological foreshadowing for students to reduce the fear of students in the process of experiment.

Process Control of Experimental Operation. Toxicology is a course with strong operability. It is centered on the toxicological evaluation in general. The experimental operation is the core of course. In order to improve the operating skill of students, the experiment course adopts the process control. We require each student to stick the label with their name on lab coat. In the process of experiment, the teacher can supervise students to do experiment directly and give them mark based on their attitude for experiment. Meanwhile, in order to make every student to understand the operating points of experiment completely, each of them is required to watch the experimental operation beside the platform closely and explain the key points of experimental operation for each step over and over. All the students are required to operate all the animal experiments one time on the platform independently, and then instructed by the experimental teacher. On the one hand, the experimental teacher can correct mistakes timely to avoid danger. On the other hand, this ensures the student willing to operate can be instructed separately. (We can't require everyone to operate mandatorily because the experiment has a certain danger.) The above measures have ensured that the students can grasp the experimental skill sufficiently. The current high use ratio of animal room in our college has verified the operating ability of students.

Timely Summarization of Experimental Problem. Each group reports the experimental result after the experiment course is completed. The result is taken as a part of experimental score. For instance, there is differentiation and analysis for micronucleus cell in the micronucleus test of marrow cells of mouse. There are only 5 micronucleus cells per 1000 polychromatic erythrocytes. It is difficult to seek it. The students are lack of initiative. Consequently, our test stipulates that the group will be awarded 5 scores if some student in this group finds micronucleus polychromatic erythrocytes. In this way, the students are very active and serious. Some groups are not willing to leave the laboratory even to 12:00 o'clock at evening due to failure to find it. After the experiment is completed, ask question based on the experiment content. The student answering it correctly will be given awarded marks. Meanwhile, timely summarize the problems encountered by students in the process of experiment. This can change the phenomenon that the problems in the process of experiment are not solved when the experiment is finished.

Assessment System Reform of Experiment. The assessment system of experiment taking experimental report as the leading indicator has been reformed. In such system, the students can get 70 basic scores based on the perfect attendance and the submission of experimental report. The former accounts for 40 and the latter, 30. In score deduction, 10 scores will be subtracted per one absenteeism among 4 experiments. 2 scores will be subtracted when being late once. In experimental class, 2 scores also will be subtracted when not listening attentively, chatting and peeking at mobile phone etc. once. In score adding, each group can be awarded 1 to 5 scores one 
time if their experiment result is excellent and the operation normative. When answering question correctly, award 1 to 2 scores. The student's initiative and participation for experiment have been improved obviously through the reform of assessment system.

The toxicological experiment course has obtained the recognition from most students through the above experimental reform. The interest of students for this course also has been improved obviously. We hope this pattern can be further promoted based on a further improvement.

\section{References}

[1] Y.Z. Zhao, G.C. Xu and X.M. Zhao. The Application of PBL Teaching Method in Experimental Teaching of Toxicology[J].Journal of Henan Medical College for Staff and Workers,2013,(2)211-213. In Chinese.

[2] W.B. Liu, L. Ao, Z.H. Cui , J.Y. Liu and J. Cao. Application of Problem-based Learning (PBL) Teaching Pattern in Toxicology Experiment Teaching[J].Progress in Modern Biomedicine,2013,(20)3965-3967. In Chinese.

[3] B.N. Qi, J. Meng, Z.G. Zhang, et al. Reform of Basic Experimental Teaching Methods of Toxicology[J].Practical Preventive Medicine,2012,(11)1753-1755. In Chinese. In Chinese.

[4] W.B. Liu, Z.H. Cui, X.Y. Yuan, J.Y. Liu and J. Cao. Reform and Thinking of Experiment Teaching of Food Toxicology[J].Progress in Modern Biomedicine ,2013,(6)1157-1159.

[5] H.Y. Li, H.Chen, j.1. Zhu, S.Y. Wu, J.L. Chen and J.L. Wang. Analysis of influencing factors and measures of designing experiment teaching in toxicology[J].CHINA MEDICAL HERALD,2013,(28)162-164. In Chinese.

[6] R. Ren, Y. Zhang, S.H. Gao, et al. Application of problem-based learning in the basic toxicology teaching[J].Basic Medical Education,2012,(9)666-669. In Chinese. 